\title{
Incidence of falls and fall-related outcomes among people in aged-care facilities in the Lower Hunter region, NSW
}

\section{Richard E. Gibson ${ }^{\mathrm{A}, \mathrm{B}, \mathrm{C}}$, Mandy Harden ${ }^{\mathrm{B}}$, Julie Byles ${ }^{\mathrm{A}}$ and John Ward ${ }^{\mathrm{B}}$}

AResearch Centre for Gender Health and Ageing,

Faculty of Health, University of Newcastle

${ }^{\mathrm{B}}$ Hunter New England Area Health Service

${ }^{\mathrm{C} C o r r e s p o n d i n g}$ author. Email: richard.gibson@newcastle.edu.au
Injuries resulting from falls, particularly hip fractures, are a major public health issue and will become more so with the ageing of the population. Of all falls resulting in hip fracture, about $35 \%$ occur in residents of aged-care residential facilities. ${ }^{1,2}$ Each year, the John Hunter Hospital, the major tertiary referral hospital for what was previously the Hunter Area Health Service, admits around 400 patients aged 65 years and over with a fractured neck of femur (R Gibberd, personal communication, February 2006). Our experience suggests that around one-third of these patients are admitted from residential care facilities. One-third of this group comes from hostels and utilises about 4500 bed-days, while the two-thirds that come from nursing homes have much shorter stays and use about 1500 bed-days (Kichu Nair, personal communication, April 2007).

On this basis, we calculate that, at a cost of $\$ 500$ per bedday, hip fractures from aged-care facilities in the former Hunter Area Health Service could cost around \$3 000000 each year. The potential savings from the prevention of hip fractures are large in terms of health care resources and cost. Moreover, the incidence of falls can be up to three times higher among residents of aged-care facilities compared to the local community, with rates in aged-care facilities being reported as 1.4 falls per person per year, rising to 6.2 falls per person per year in a psychogeriatric ward. ${ }^{3}$ In an Australian study, 625 residents of hostels and nursing homes in three states were followed for two years. Over that period, 1555 falls were reported among 355 of these residents. $^{4}$

The aim of this study was to describe reports of falls and fall-related outcomes among people in residential agedcare facilities in the Lower Hunter region of New South Wales (NSW).

\section{Methods}

All aged-care facilities in the former Hunter Area Health Service and the Lower Mid North Coast Cluster of the Hunter New England Area Health Service were invited to participate in this study. Facilities with 20 or more beds were included (facilities with less than 20 beds were considered to be atypical). In June 2005, each facility provided data on the number of beds by type. All beds were assumed to be occupied and the number of beds, assumed to be fixed, was used to determine the denominator in the analyses. An index of the turnover of individuals within this fixed size population was obtained from monthly data on the number of new permanent and respite admissions. Further, the characteristics of participating facilities were determined at a census in January 2006. In this census, each facility provided details of all permanent residents, including their date of birth, sex, whether they were ambulant or not, whether they were residing in a dementiaspecific unit or not and resident classification scale (RCS). Each new resident was assigned to one of eight RCS categories designed to reflect their level of need.

Using a standard form, each facility provided monthly aggregate data describing the number of falls (not the number of residents who experienced a fall, as each resident could register multiple falls) and the number of falls reported in residents' charts that resulted in adverse events such as fracture, hospitalisation or death. Each facility designated a senior staff member to supervise the project 
within their facility and to collect the monthly data. The staff member audited residents' charts to identify 'incident records', which report details of fall incidents including date, time, injury, immediate treatment and medical treatment by facility staff. Cumulative data from the monthly falls reports showed the total number of reported falls for that month as well as: the number of falls resulting in fracture; fractured neck of femur; fractured neck of femur within three months of admission; hospitalisation due to a fall-related injury; and the number of deaths occurring within three months of fractured neck of femur. Where a facility failed to provide a monthly falls report, the designated staff member was sent a second form by email or fax then followed up by telephone.

Not all facilities returned forms every month. The rate of falls and related events occurring each month was determined by dividing the number of events by the total number of beds for all facilities that had returned forms for that month. The total number of beds for each month was summed to provide the overall denominator as bed-months of observation.

\section{Results}

In total, 98 facilities were identified in the Lower Hunter region. Of these, six were ineligible due to small size, four declined to participate in the study and 88 consented to participate (consent rate of approximately $96 \%$ if ineligible facilities are excluded). Characteristics of the facilities are shown in Table 1 and characteristics of the residents are shown in Table 2.

The median and mean number of new permanent admissions each month at each facility was 2 and 2.3 (range: 0-28), and the median and mean number of new respite admissions each month at each facility was 2 (range: $0-10$ ).

Falls data forms were collected and collated for the period July to December 2005. Over this 6-month period, forms were returned by $75-93 \%$ of facilities each month, with an overall return rate for the period of $84 \%$. There was no systematic bias in returns according to type of facility. The total bed-months of observation was 28536.

The trend in the rate of falls and related events for every 1000 beds is shown in Figure 1. The overall crude incidence rate was 171 falls: 2.4 falls with fractured neck of femur; and 2.2 falls with other fracture injury for every 1000 bed-months of observation. The crude overall incidence rate for hospitalisation from a fall was 6 per 1000 bed-months of observation.

The outcomes of the falls are shown in Table 3 where rates are expressed for every 1000 falls. Overall, 3.6\% of falls required hospital admission, $1.4 \%$ of falls resulted in a fractured neck of femur and a similar proportion resulted in other fracture. For every 14 fractured neck of femur events, 1.8 occurred within the first three months following admission (13\%); that is, a rate ratio of $1.8: 14$. The rate of death within three months of a fractured neck of femur was $35 \%$ of the rate of falls with fractured neck of femurthat is, a rate ratio of around $1: 3$ - indicating a high mortality rate among residents experiencing fractured hip.

\section{Discussion}

These data were collected before an intervention for falls prevention in aged-care facilities was implemented at the

Table 2. Characteristics of the residents in 88 aged-care facilities in the Lower Hunter region of NSW at the time of the census, January $2006(N=5354)$

\begin{tabular}{ll} 
Age in years: median (range) & 85 (27-107) \\
Female (\%) & 73 \\
Ambulant* (\%) & 70 \\
Dementia-specific care (\%) & 21 \\
\hline $\begin{array}{l}\text { *Ambulant defined as anyone who can stand and walk with or } \\
\text { without assistance. }\end{array}$
\end{tabular}

Table 1. Distribution and characteristics for low-care, high-care and mixed-care beds in participating resident aged-care facilities in the Lower Hunter region of NSW, 2005-2006

\begin{tabular}{|c|c|c|c|c|c|c|c|c|c|c|c|c|c|}
\hline \multirow[t]{2}{*}{$\begin{array}{l}\text { Type of } \\
\text { care }\end{array}$} & \multirow[t]{2}{*}{$\begin{array}{c}\text { Facilities } \\
n\end{array}$} & \multicolumn{2}{|c|}{$\begin{array}{l}\text { Median } \\
\text { number } \\
\text { general beds }\end{array}$} & \multicolumn{2}{|c|}{$\begin{array}{l}\text { Median number } \\
\text { dementia } \\
\text { specific beds }^{+}\end{array}$} & \multicolumn{2}{|c|}{$\begin{array}{l}\text { Median } \\
\text { number } \\
\text { all beds }\end{array}$} & \multicolumn{2}{|c|}{$\begin{array}{l}\text { Median number } \\
\text { new admissions } \\
\text { per month* }\end{array}$} & \multicolumn{2}{|c|}{$\begin{array}{l}\text { Median number } \\
\text { respite admissions } \\
\text { per month* }\end{array}$} & \multicolumn{2}{|c|}{$\begin{array}{l}\text { Median } \\
\text { RCS }^{* *}\end{array}$} \\
\hline & & $n$ & Range & $n$ & Range & $n$ & Range & $n$ & Range & $n$ & Range & $n$ & Range \\
\hline Low care & 42 & 40 & $0-78$ & 0 & $0-65$ & 40 & $25-132$ & 1 & $0-28$ & 2 & $0-9$ & 5 & $1-8$ \\
\hline High care & 24 & 60 & $28-136$ & 0 & $0-96$ & 65 & $28-216$ & 3 & $0-12$ & 0 & $0-9$ & 2 & $1-7$ \\
\hline $\begin{array}{l}\text { Mixed (low } \\
\text { and high) }\end{array}$ & 22 & 68 & $37-130$ & 10 & $0-46$ & 8 & $44-160$ & 2 & $0-17$ & 2 & $0-10$ & 3 & $1-8$ \\
\hline \multicolumn{14}{|c|}{$\begin{array}{l}\text { *Data obtained from monthly reports from facilities. } \\
\text { **Data obtained from a census of residents in January } 2006 . \\
\text { RCS: Resident Classification Scale. }\end{array}$} \\
\hline
\end{tabular}


beginning of 2006. The data were aggregated in facilities and so are not age specific and include a wide age range. Additionally, the data were reported by the facilities and accuracy, therefore depends on procedures and protocols
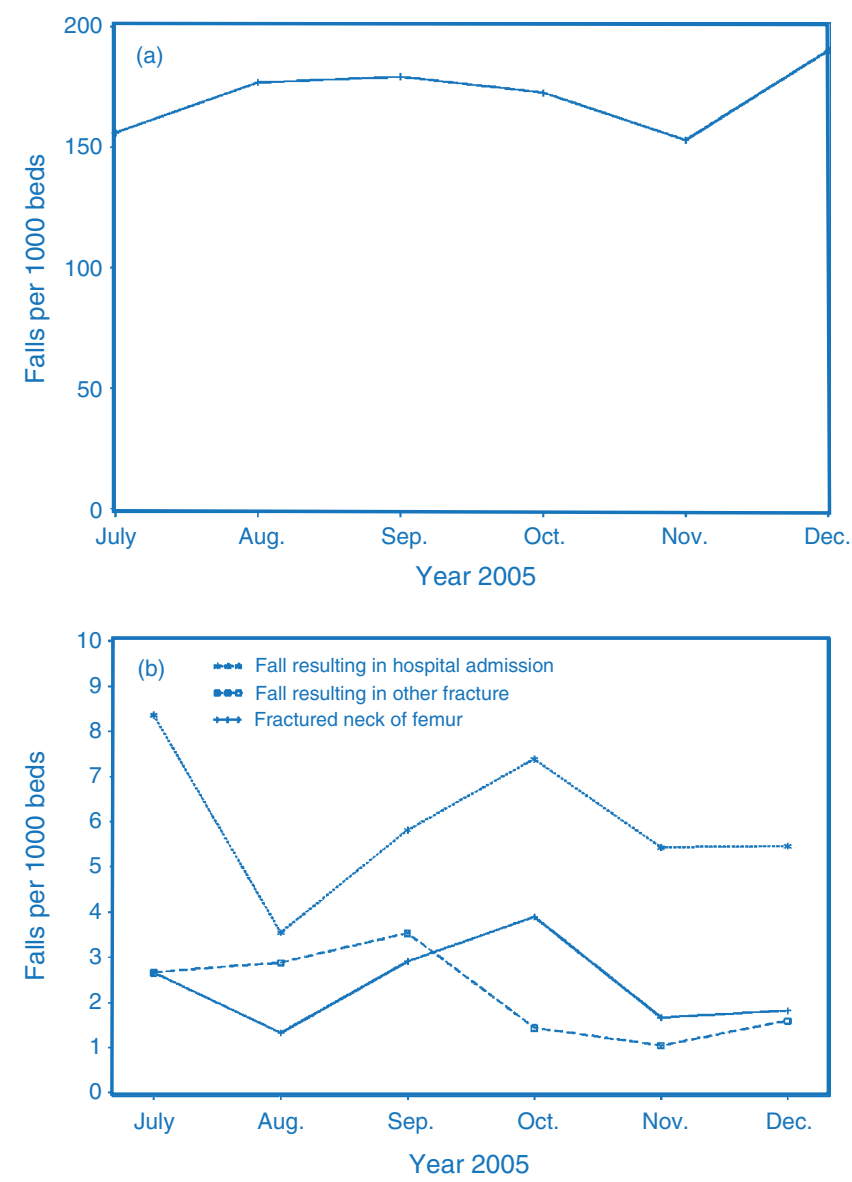

Figure 1. Falls per 1000 beds among residents of aged-care facilities in the Lower Hunter region of NSW for the period July 2005 to December 2005. (a) Rate of total falls. (b) Rate of falls resulting in hospital admission, fractured neck of femur and other fracture. for incident reporting at each facility. The true number of falls may be higher or lower than reported.

We assumed that bed numbers remained fixed and that all beds were occupied for the duration of the study. While the assumption of full beds is reasonable, some facilities increased bed numbers during the period, possibly resulting in an overestimation of rates per 1000 beds. Similarly, if falls were under-reported in these data then the denominator for rates per 1000 falls should be larger and the rates may have been overestimated. Furthermore, we observed a decrease in the response rate over time and there was possible under-reporting by facilities where no falls occurred in a month (or by facilities with many falls). Under-reporting would bias both the denominator and the numerator. In contrast, we experienced a high rate of facility enrolment in the study and participation was generally strong (given the limitations of time and resources experienced by these facilities).

Given these limitations, the data demonstrated a rate of 171 falls for every 1000 beds for each month. Extrapolating across a 12-month period, this is equivalent to two falls per bed for every year. This is higher than would be expected in the community; for example, Mackenzie et al. reported a rate of 47 per 1000 people each month. ${ }^{4,5}$ The rate of falls observed here in residential settings are comparable to an Australian study by Flicker et al., where a crude rate of 155 per 1000 people every month was observed (calculated from data provided). ${ }^{6}$ In addition, a Scandinavian study found a much higher rate of 357 per 1000 person-months among residents with dementia compared with residents of senior citizens apartments (142 per 1000 person-months) and residents of an old people's home (176 per 1000 person-months). ${ }^{7}$ Around $3.6 \%$ of falls reported in our study resulted in hospital admission. Among those admitted to

Table 3. Monthly total number of beds and falls in residential care facilities and rate of falls outcomes per 1000 falls for July-December 2005 in the Lower Hunter region of NSW

\begin{tabular}{|c|c|c|c|c|c|c|c|c|c|}
\hline \multirow[t]{3}{*}{ Month } & \multirow{3}{*}{$\begin{array}{c}\text { Beds } \\
\text { N }\end{array}$} & \multirow{3}{*}{$\begin{array}{c}\text { Falls } \\
\qquad N\end{array}$} & \multicolumn{5}{|c|}{ Outcomes per 1000 falls } & \multirow{2}{*}{\multicolumn{2}{|c|}{$\begin{array}{l}\text { Returns received } \\
\text { from facilities } \\
\text { contributing data }\end{array}$}} \\
\hline & & & \multirow[t]{2}{*}{$\begin{array}{l}\text { Hospital } \\
\text { admission }\end{array}$} & \multirow{2}{*}{$\begin{array}{c}\text { Fractured } \\
\text { neck of } \\
\text { femur }\end{array}$} & \multirow[t]{2}{*}{$\begin{array}{l}\text { Other } \\
\text { fracture }\end{array}$} & \multirow{2}{*}{$\begin{array}{l}\text { Fractured neck } \\
\text { of femur within } \\
3 \text { months of } \\
\text { admission } \\
\text { to facility }\end{array}$} & \multirow{2}{*}{$\begin{array}{l}\text { Deaths within } \\
3 \text { months of } \\
\text { fractured neck } \\
\text { of femur }\end{array}$} & & \\
\hline & & & & & & & & $n$ & $\%$ \\
\hline July & 5288 & 830 & 53 & 17 & 17 & 3.6 & 3.6 & 82 & 93 \\
\hline August & 4491 & 807 & 21 & 7.4 & 17 & 1.2 & 6.2 & 72 & 82 \\
\hline September & 4822 & 863 & 32 & 16 & 20 & 1.2 & 5.8 & 74 & 84 \\
\hline October & 4898 & 840 & 43 & 23 & 8.3 & 1.2 & 4.8 & 74 & 84 \\
\hline November & 4786 & 731 & 36 & 11 & 6.8 & 0.0 & 2.7 & 74 & 84 \\
\hline December & 4251 & 799 & 29 & 10 & 7.5 & 3.8 & 6.3 & 66 & 75 \\
\hline Totals & 28536 & 4870 & - & - & - & - & - & 442 & 84 \\
\hline $\begin{array}{l}\text { Overall } \\
\text { monthly rate }\end{array}$ & - & - & 36 & 14 & 13 & 1.8 & 4.9 & & \\
\hline
\end{tabular}


hospital, around $40 \%$ were reported to have a fractured neck of femur, and we observed a high rate of death within three months of fracture. Moreover, we observed that on average over the six months, an estimated $13 \%$ of falls that resulted in a fractured neck of femur occurred within three months of admission.

The data revealed a rate of falls among residents of agedcare facilities that can be improved. We intend to work with facilities involved in the study to improve monthly reporting of falls and falls injuries. Additionally, we have enrolled a cohort of around 5000 residents in participating facilities and will be able to observe falls resulting in a fractured neck of femur at an individual level. Crosschecking patient information data for admissions with a fractured neck of femur will allow more accurate reporting of this injury in our routine data collection activities.

The results of this preliminary ecological study indicate a need for falls injury prevention in residential aged-care facilities.

\section{Acknowledgments}

Funding for data collection was provided by NSW Health and is part of a Health Promotion Demonstration Project. This paper is prepared by the authors on behalf of the research team. Researchers in the Faculty of Health at the University of Newcastle and in the Hunter New England Area Health Service are members of the Hunter Medical Research Institute.

\section{References}

1. Fisher AA, Davis MW, Smith PN. Undertreatment of osteoporosis following hip fracture. J Bone Joint Surg Am 2003; 85-A(7): 1394-5.
2. Fisher AA, Davis MW, McLean AJ, Le Coutteur DG. Epidemiology of falls in elderly semi-independent residents in residential care. Australas J Ageing 2005; 24(2): 98-102. doi:10.1111/j.1741-6612.2005.00081.x

3. Cameron I, Murray GR, Gillespie LD, Cumming RG, Robertson MC, Hill K, Kerse N. Interventions for preventing falls in older people in residential care facilities and hospitals (Protocol). Cochrane Database of Systematic Reviews 2005; 3: CD005465.

4. Hill K, Vrantisidis F, Haralambous B, Fearn M, Smith R, Murray K et al. An analysis of research on preventing falls and falls injury in older people: Community, residential care and hospital settings (2004 update). Report to the Australian Government, Department of Health and Ageing, Injury Prevention Section by the National Ageing Research Institute. Canberra: Commonwealth of Australia; 2004. Available at: http://www.health.gov.au/internet/main/publishing.nsf/Content/ health-pubhlth-publicat-document-falls_community-cnt.htm (Cited 30 October 2008.)

5. Mackenzie L, Byles J, D'Este C. Validation of self-reported fall events in intervention studies. Clin Rehabil 2006; 20(4): 331-9. doi:10.1191/0269215506cr947oa

6. Flicker L, MacInnes RJ, Stein MS, Scherer SC, Mead KE, Nowson CA et al. Should older people in residential care receive vitamin D to prevent falls? Results of a randomized trial. J Am Geriatr Soc 2005; 53: 1881-8. doi:10.1111/ j.1532-5415.2005.00468.x

7. Jenson J, Lundin-Ollson L, Nyberg L, Gustafson Y. Falls among frail older people in residential care. Scand J Public Health 2002; 30: 54-61. 